OPEN ACCESS

Edited by:

Shripad T. Revankar

Purdue University, United States

Reviewed by:

Omid Noori-kalkhoran,

Cardiff University, United Kingdom

Xiaojing Liu,

Shanghai Jiao Tong University, China

*Correspondence:

Ataollah Rabiee

rabiee@shirazu.ac.ir

Specialty section:

This article was submitted to

Nuclear Energy,

a section of the journal

Frontiers in Energy Research

Received: 09 February 2021

Accepted: 12 April 2021

Published: 19 May 2021

Citation:

Salmassian B, Rabiee A, Nematollahi MR, Faghihi F and

Pirouzmand A (2021) Transient

Parameter Analysis of Non-scrammed Local Melting Accidents - A WER

1000 Case Study.

Front. Energy Res. 9:666032. doi: 10.3389/fenrg.2021.666032

\section{Transient Parameter Analysis of Non-scrammed Local Melting Accidents-A VVER 1000 Case Study}

\author{
Behzad Salmassian ${ }^{1}$, Ataollah Rabiee ${ }^{*}$, Mohammad R. Nematollahi ${ }^{1}$, Farshad Faghihi',3 \\ and Ahmad Pirouzmand ${ }^{1}$
}

${ }^{1}$ Department of Nuclear Engineering, School of Mechanical Engineering, Shiraz University, Shiraz, Iran, ${ }^{2}$ Radiation Research Center, Shiraz University, Shiraz, Iran, ${ }^{3}$ Ionizing and Non-lonizing Research Center, Shiraz University of Medical Science, Shiraz, Iran

The first stage of a core degradation-based on the defense-in-depth concept of nuclear power plant (NPP) safety - is prone to fuel melting due to local blockage. The flow blockage accidents with no SCRAM happening can lead to a local fuel-clad failure, consequently affecting the safety of NPP. The present study provides an analysis of Anticipated Transient Without SCRAM (ATWS), which might lead to a condition of burning out. The accidents related to the ATWS scenarios, detailed in the case of WER-1000/N446 reactor FSAR (Final Safety Analysis Report), include pump failure, local blockage, relative power increase, and a combination of these transients. In this research, first, drawing upon MCNPX 2.7 and COBRA-EN codes, a coupling framework is developed and then validated using an authentic reference point. The obtained results reveal that the reactor SCRAM does not occur while accidents are being investigated as there is a $10 \%$ difference in the mass flow rate reduction, a $470 \mathrm{kPa}$ in the channel pressure drop, and a $204^{\circ} \mathrm{K}$ in the clad temperature, which constitute limitations under most pessimistic scenarios. However, under these conditions, a 70\% void fraction over 12 min is observed in certain channels. Hence, burnout and local fuel melting could occur under normal operational and ATWS circumstances. According to uncertainty analyses, the occurrence of the void fraction above zero is locally definite. The transient analysis outputs could be deployed as monitoring system inputs and exploited for identifying weak points in the system.

Keywords: fuel failure, local flow blockage, VVER1000, transient analysis, ATWS accidents

\section{INTRODUCTION}

The ratio of heat removal/heat generation to the local or generalized flow reduction is the most significant and hazardous condition that threatens the safety of a nuclear power plant (NPP). This could happen locally due to a flow blockage accident, including pump failure, or blockage at the channel entrance or in the middle of cooling channels between fuel rods. The blockages could develop as a consequence of the particles remaining from maintenance procedures, broken parts separated from the reactor structure, or in an otherwise manner through swelling, bending, boing, or displacement of fuel elements. The local flow blockage accidents have a local characteristic and do not bring about any changes in total reactivity, core transient flow, or total heat absorption 


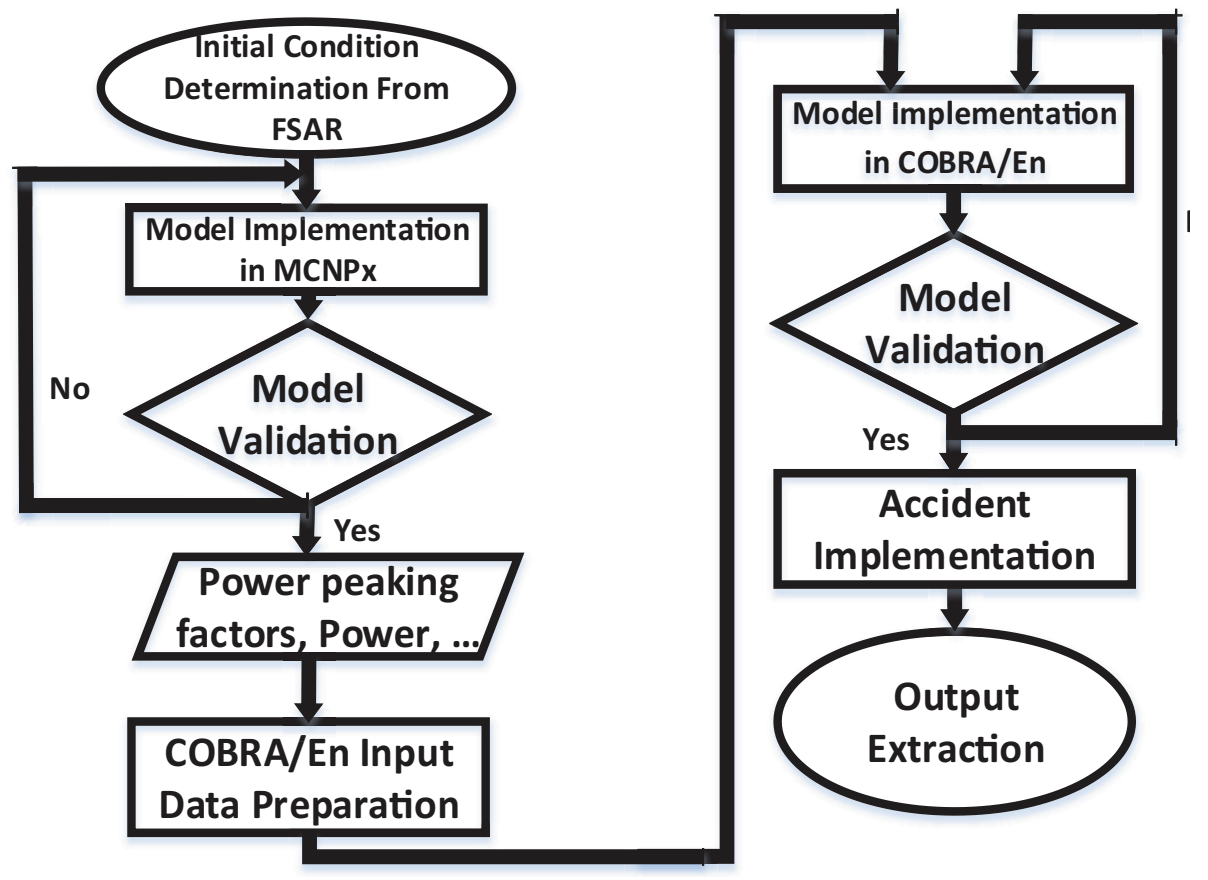

FIGURE 1 | Methodology algorithm.

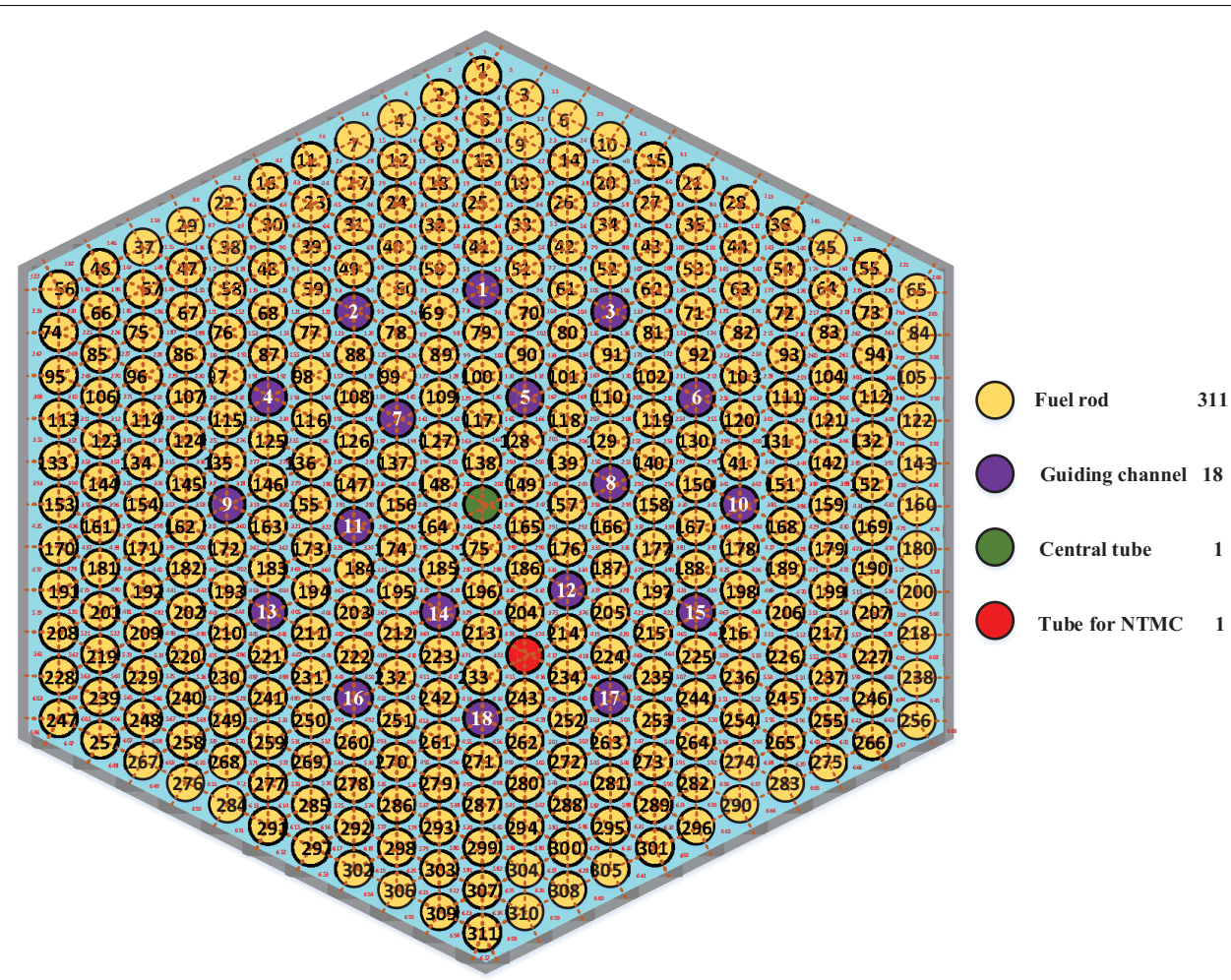

FIGURE 2 | WER1000/446 core fuel assemblies' placement. 


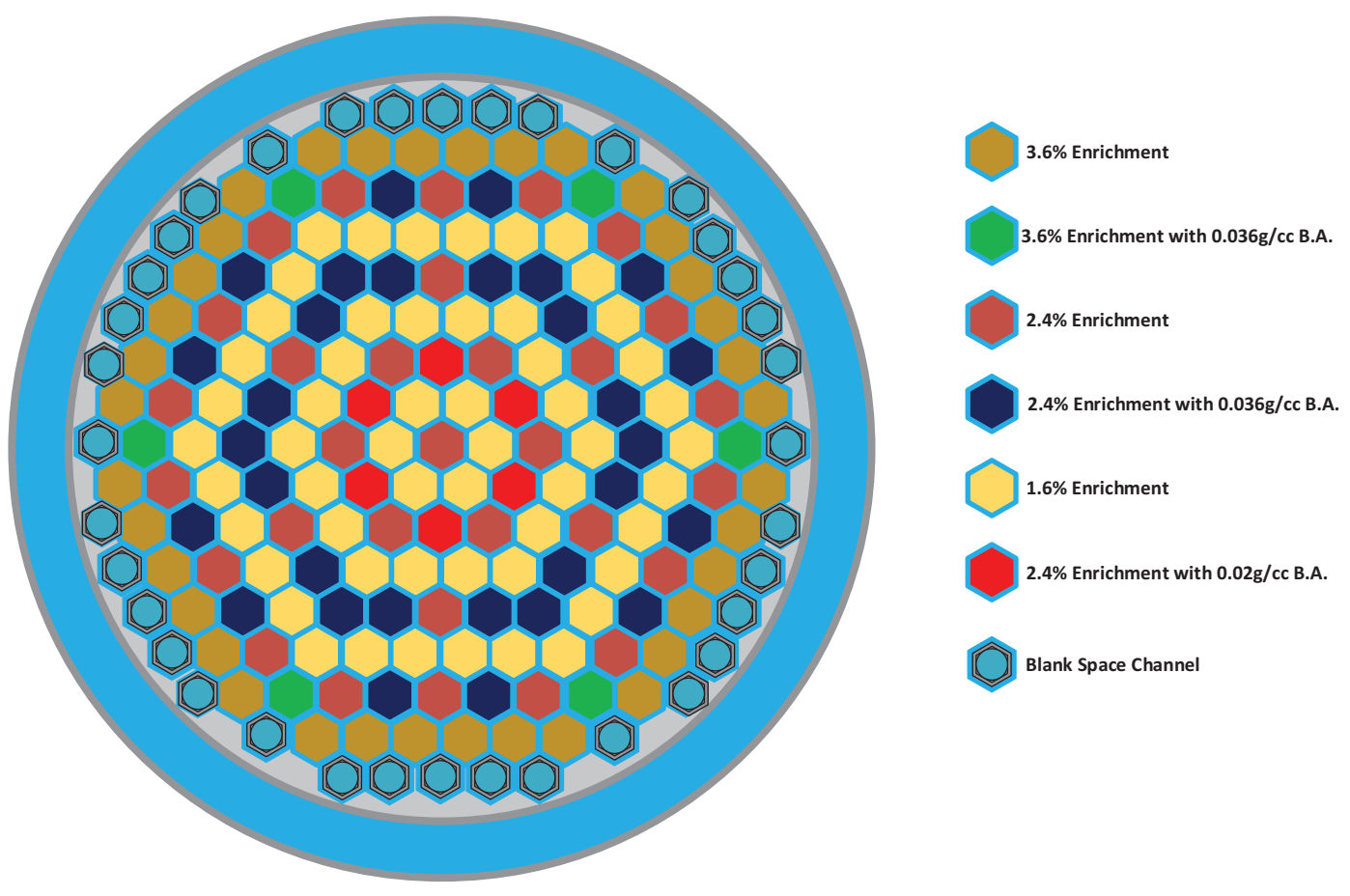

FIGURE 3 | VVER1000/446 core fuel enrichment placement.

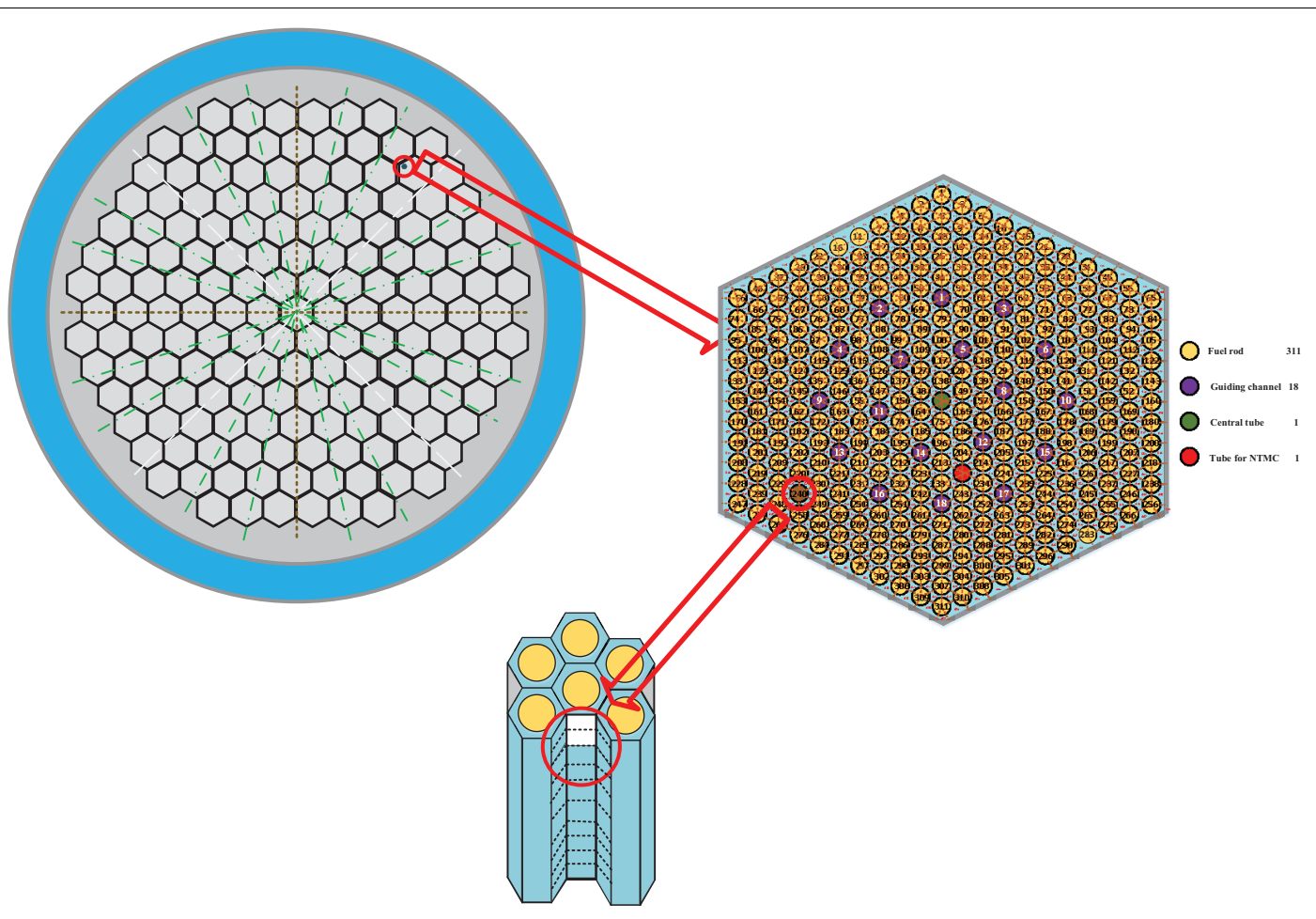

FIGURE 4 | Local blockage accident location. 
TABLE 1 | Input specifications for COBRA-EN code.

\begin{tabular}{|c|c|c|c|}
\hline $\begin{array}{l}\text { Number of } \\
\text { coolant channels }\end{array}$ & $163 \#$ & $\begin{array}{l}\text { Number of spacer } \\
\text { grid positions }\end{array}$ & $10 \#$ \\
\hline Inlet temperature & $546.15 \mathrm{~K}$ & $\begin{array}{l}\text { Average inlet mass } \\
\text { flux for fuel } \\
\text { channels }\end{array}$ & $4,158.4 \mathrm{~kg} / \mathrm{s} / \mathrm{m}^{2}$ \\
\hline Exit pressure & $15.7 \mathrm{MPa}$ & $\begin{array}{l}\text { Inlet Boron } \\
\text { concentration for } \\
\text { coolant channels. }\end{array}$ & 1,162 ppm \\
\hline $\begin{array}{l}\text { Number of rods in } \\
\text { assembly }\end{array}$ & $311 \#$ & $\begin{array}{l}\text { Number of coolant } \\
\text { channels in } \\
\text { assembly }\end{array}$ & $657 \#$ \\
\hline
\end{tabular}

TABLE 2 | Input specification for MCNPX 2.7 code.

\begin{tabular}{lccc}
\hline No. Fuel assembly & $\mathbf{1 6 3} \#$ & Core height & $\mathbf{3 5 5} \mathbf{~ C m}$ \\
\hline Clad material & $\mathrm{Zr}+\mathrm{Nb}$ & Fuel material & $\mathrm{UO}_{2}$ \\
Control rod material & $\mathrm{B}_{4} \mathrm{C}+$ Dy2O3TiO2 & Core power & $3,000 \mathrm{MW}$
\end{tabular}

TABLE 3 | Reactor SCRAM conditions.

\begin{tabular}{l}
\hline RCP pump failure Loss of feed water flow \\
\hline Drop of pressure differential \\
RCPS from 0,245 to 0,392 \\
MPa for the time less than $5 \mathrm{~s}$ \\
DNBR is less than 1,2 \\
Pressure above the core is \\
more than $17,5 \mathrm{MPa}$ \\
The temperature in any hot leg \\
exceeds $t$ nom $+8^{\circ} \mathrm{C}$ \\
\hline
\end{tabular}

capacity. Local flow blockages reduce the coolant channel crosssection, which subsequently first there would be a decrease in the heat transfer coefficient followed by a rise in the local temperature. What is noticed is that the clad temperature rises to supersaturation level, the DNBR (departure from nucleate boiling ratio) limit is broken, bubbles form in the coolant, and the void fraction rises above zero. Eventually, fuel and clad parts, having more power generation density, come to melt locally like in a candle; molten fuel may enter the coolant and form a solid mass. Reduction in the cooling flow rate increases the hydraulic resistance, leading to the continuation of the above events, which, in turn, causes more fuel melting. This positive feedback can cause the melting to continue up until the system reaches local equilibrium or expands till the occurrence of a SCRAM situation (Nakamura, 2014). Zhang et al. (2019) reported that heat fluctuations, steam creation, and biphasic could bring about fractures in the fuel cladding, which alternately, could generate further blockage in the system. Lewis et al. acknowledged the difficulty of simulating and diagnosing a local blockage accident due to its local nature. Diagnosing a local blockage accident is possible when it is extended affecting the coolant flow or the core reactivity. Therefore, existing monitoring systems are unable to diagnose local blockage mishaps (Lewis, 1977).

The following section devoted the literature review makes a survey of those studies which deal with local blockage
TABLE 4 | ATWS scenarios.

\begin{tabular}{|c|c|c|}
\hline Event No & Scenario abbreviation & Event frequency \\
\hline ATWS 1 & One RCP pump failure & 3 time/Reactor cycle \\
\hline ATWS 2 & $\begin{array}{l}\text { Relative power increase up } \\
\text { to } 17 \%\end{array}$ & $10^{-1}$ time/reactor cycle \\
\hline ATWS 3 & $\begin{array}{l}90 \% \text { Blockage in hot } \\
\text { channel entrance }\end{array}$ & Common \\
\hline ATWS 4 & $\begin{array}{l}\text { Relative power increase up } \\
\text { to } 17 \%+90 \% \text { blockage in } \\
\text { hot channel middle }\end{array}$ & $8 \times 10^{-2}$ time/reactor cycle \\
\hline ATWS 5 & $\begin{array}{l}\text { One RCP pump } \\
\text { breakdown }+90 \% \\
\text { Blockage in hot channel } \\
\text { entrance }\end{array}$ & $6 \times 10^{-2}$ time/Reactor cycle \\
\hline ATWS 6 & $\begin{array}{l}\text { One RCP pump } \\
\text { breakdown }+90 \% \\
\text { Blockage in hot channel } \\
\text { entrance }+ \text { Control rod fail } \\
\text { in drop down }\end{array}$ & $10^{-2}$ time/Reactor cycle \\
\hline ATWS 7 & $\begin{array}{l}\text { Two RCP pump } \\
\text { breakdown }+90 \% \\
\text { Blockage in hot channel } \\
\text { entrance }\end{array}$ & $10^{-1}$ time/Reactor cycle \\
\hline
\end{tabular}

TABLE 5 | Validation of steady-state model.

\begin{tabular}{|c|c|c|c|}
\hline Parameters & Current study & Arshi et al., 2010 & FSAR \\
\hline $\begin{array}{l}\text { Mean coolant } \\
\text { temperature along the } \\
\text { core }(\mathrm{K})\end{array}$ & 581.7 & 583.05 & 579 \\
\hline $\begin{array}{l}\text { Mean coolant } \\
\text { temperature at core exit } \\
\text { (K) }\end{array}$ & 594.4 & 595.24 & 594 \\
\hline $\begin{array}{l}\text { Maximum fuel enthalpy } \\
(\mathrm{J} / \mathrm{kg})\end{array}$ & 256,000 & 275171 & $<963,000$ \\
\hline $\begin{array}{l}\text { Ave. pressure drop } \\
\text { along the core active } \\
\text { length }(\mathrm{Pa})\end{array}$ & - & 114,500 & NA \\
\hline $\begin{array}{l}\text { Fuel surface maximum } \\
\text { temperature }\end{array}$ & 886.7 & 887.8 & 883.4 \\
\hline $\begin{array}{l}\text { Minimum DNBR in the } \\
\text { hot leg }\end{array}$ & 1.92 & 1.86 & $>1.75$ \\
\hline
\end{tabular}

TABLE 6 | Uncertainties in results.

\begin{tabular}{|c|c|c|c|}
\hline Parameter & uncertainty & Parameter & uncertainty \\
\hline Pressure & $\pm 1 \%$ & Flow rate & $\pm 1 \%$ \\
\hline Sub-channel area & $\pm 0.5 \%$ & $\begin{array}{l}\text { Single-phase } \\
\text { mixing coefficient }\end{array}$ & $\pm 42 \%$ \\
\hline Power & $\pm 1.5 \%$ & Inlet temperature & $\pm 1.5^{\prime} \mathrm{K}$ \\
\hline $\begin{array}{l}\text { Two-phase mixing } \\
\text { coefficient }\end{array}$ & $\pm 24 \%$ & $\begin{array}{l}\text { Equilibrium } \\
\text { distribution } \\
\text { weighing factor in } \\
\text { the void drift }\end{array}$ & $\pm 14 \%$ \\
\hline
\end{tabular}

accidents. Roichwooderi et al. identified local flow blockage accidents affecting the performance of the fuel pin in the LMFBR reactor. The study concludes that severe safety hazards do not occur up to the time when six adjacent fuel rods are 


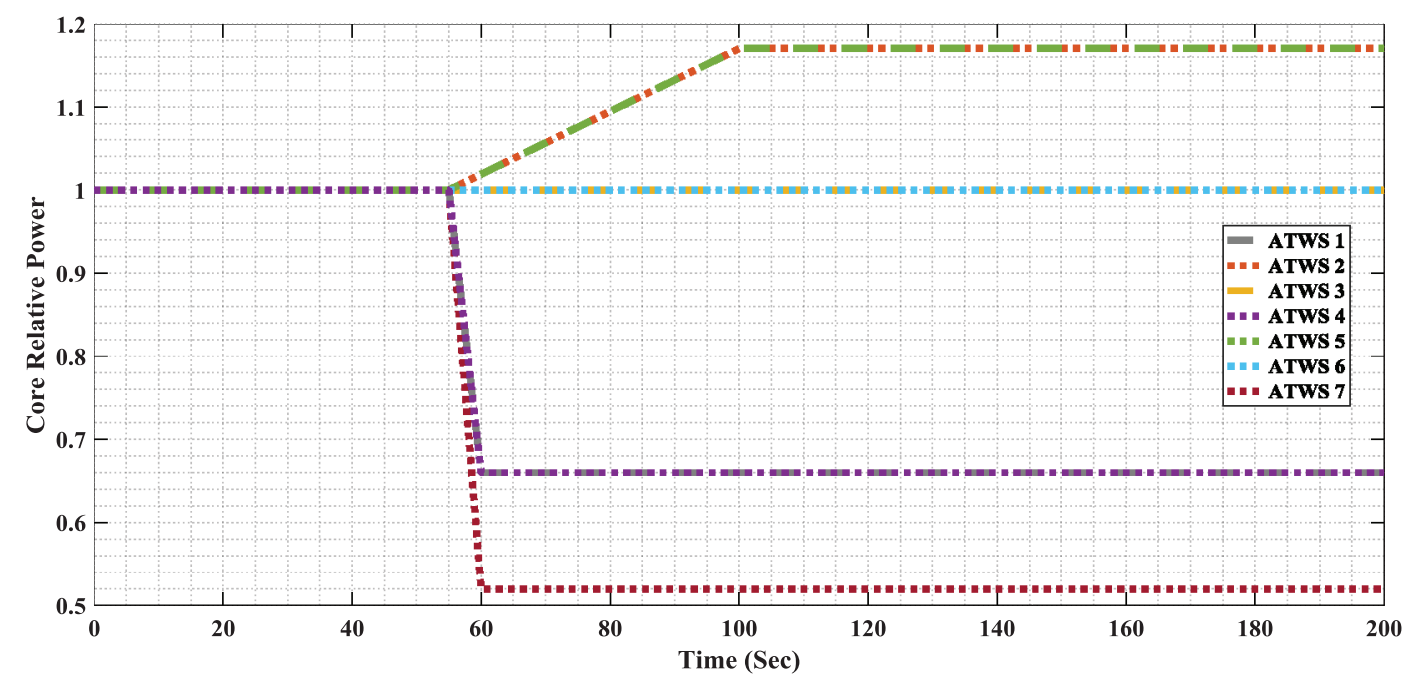

FIGURE 5 | Core relative power during ATWS scenarios.

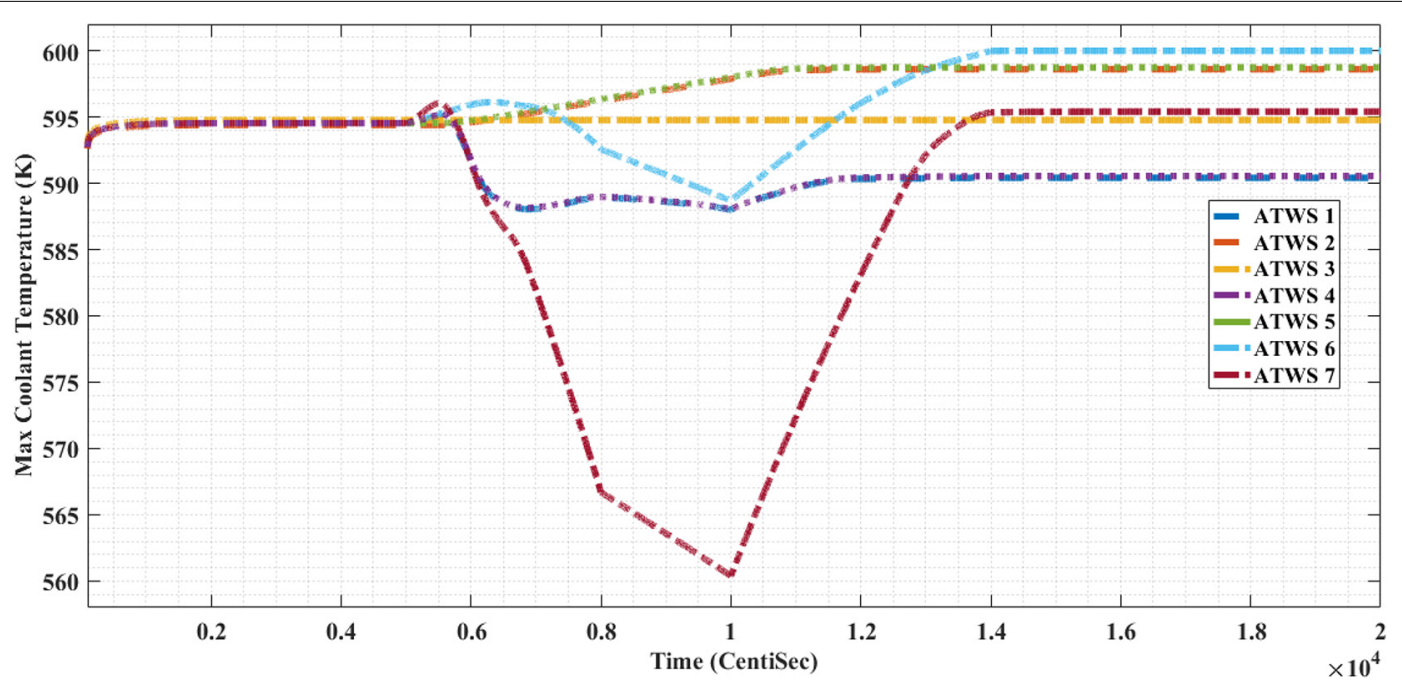

FIGURE 6 | Maximum coolant temperature during ATWS Scenarios.

burned out (Roychowdhury et al., 2000). Liu et al. analyzed five blockage accidents for a liquid metal reactor using STAR$\mathrm{CCM}+$ software, taking into consideration the effect of keeping the clad temperature below melting point (Liu et al., 2020).

Rahm et al. (2019) proposed a new design for liquid metal reactors resistant to instantaneous local blockage accidents based on a BETINa calculation code. Dow et al. examined the local flow blockage accident in sodium cooling reactors using the ATHAS-LMR code (Du et al., 2019).

Gharari et al. conducted an investigation into the local flow blockage accident at the 446/1000-VVER reactor coolant channel entrance using COBRA-EN and RELAP5 for detecting the presence and absence of the crossflow. Their obtained results indicated serious safety problems at the channel entrance with local flow blockage and cross-flow disruption
(Gharari et al., 2016). Dehjourian et al. inspected the effects of fuel rod displacement and deformation on the fuel and clad heat transfer coefficient and temperature, for 446/1000-VVER reactors using ANSYS code. The results they obtained show that with an increase in both the amount of bloating and displacement as well as an increase in the clad temperature, some fuel surfaces tend toward drying, which accident occurs in excess of safety standards. In the latter case-happening as a result of an inherent disturbance in the flux and pressure in these pointsthe probability of local flow blockage is augmented in the network maintenance points (Dehjurian, 2015).

Yuchuan et al. simulated the local flow blockage between the JPR-3M fuel plates for fuel assemblies with a measure of blockage from 30 to 95\% through RELAP5/MOD34 code. Their results indicated that local blockage occurrence neither leads to any 


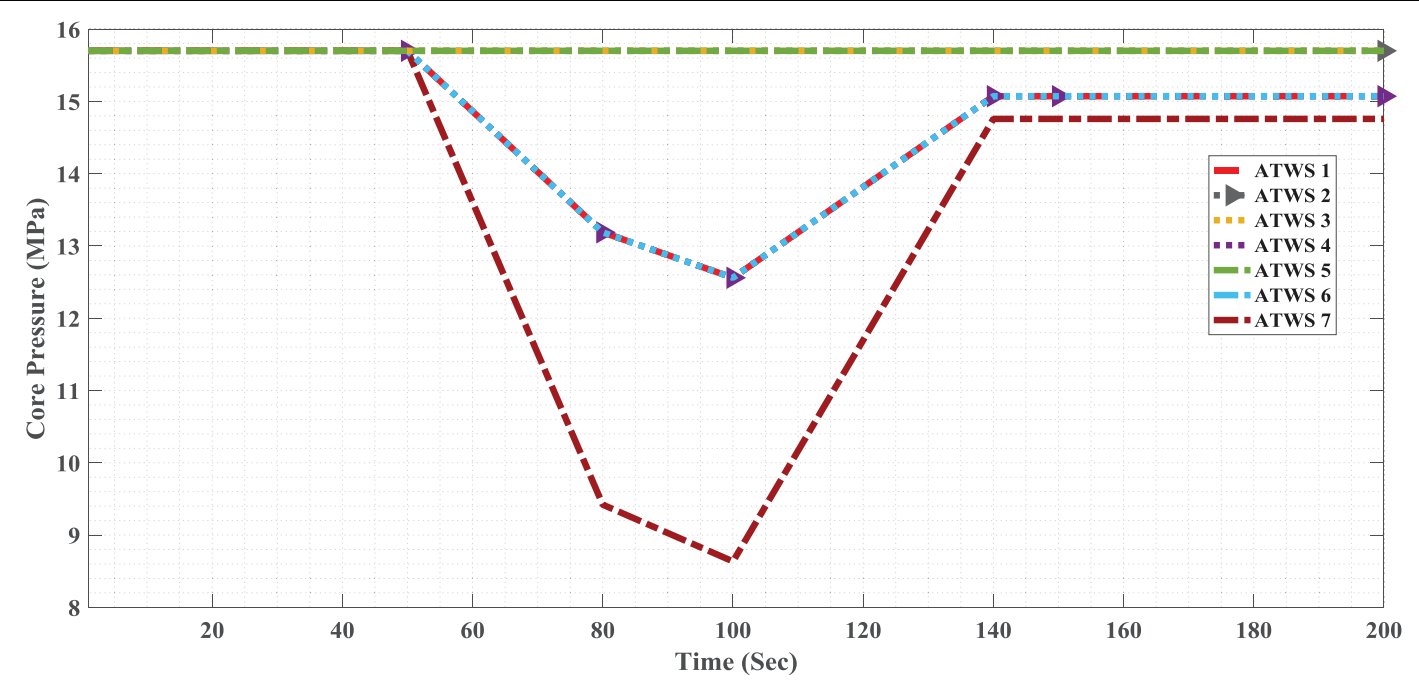

FIGURE 7 | Core pressure during ATWS scenarios.

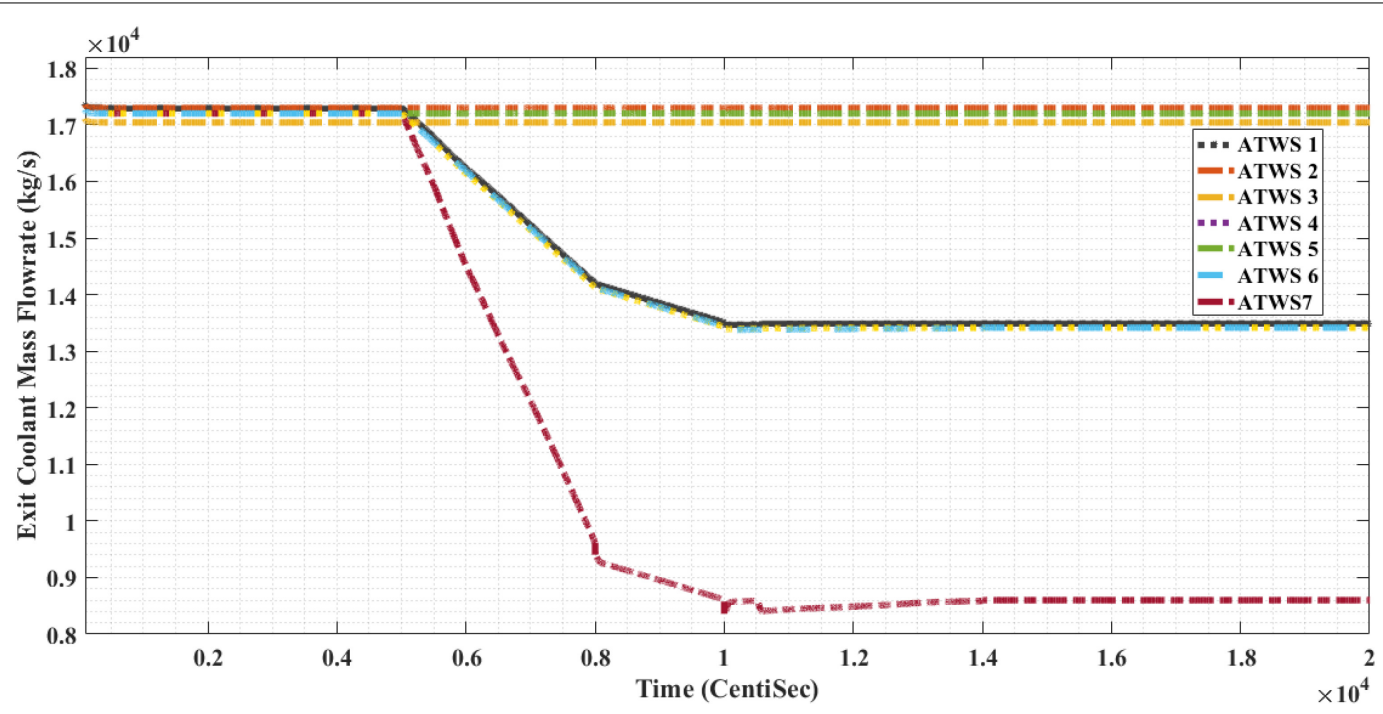

FIGURE 8 | Outlet coolant mass flow rate during ATWS scenarios.

damage to the fuel up to $70 \%$ of the channel width blockage nor does it cause any severe damage up to $95 \%$. In blockages beyond $95 \%$ of the channel width, the damage is quite severe giving rise to rupture and fuel melting. They emphasize that local flow blockage cannot be diagnosed until significant changes occur in the reactor's major parameters (Guo et al., 2018). Thus, the accidents referred to above can bring about weaknesses to the point of creating initial conditions for severe accidents.

Sehgal (2011) mentioned that the clad surface burn out, deformation, and melting range limit is 1,500 degrees. The IAEA (international atomic energy agency), in its Severe Accident Management Guideline Development, emphasized the importance of predicting, preventing, mitigating, and reducing consequences of any accident that might lead to severe accidents (Khamis, 2017). Analyzing local accidents, especially local flow blockages, is of crucial importance as they can help identify these types of accidents that cause disruptions in safety standards. To this end, this study uses COBRA-EN computational code to carry out relevant analyses.

In general, the current study set out to perform a transient analysis of accidents that might lead to the loss of COBRA-EN thermal-hydraulic calculation code coupled with MCNPX 2.7 Monte Carlo neutron code.

\section{MATERIALS AND METHODS}

To accomplish a transient analysis of local flow blockage accidents, this section is divided into four sub-sections dedicated to explaining the research procedure, tools, and case studies. First, 


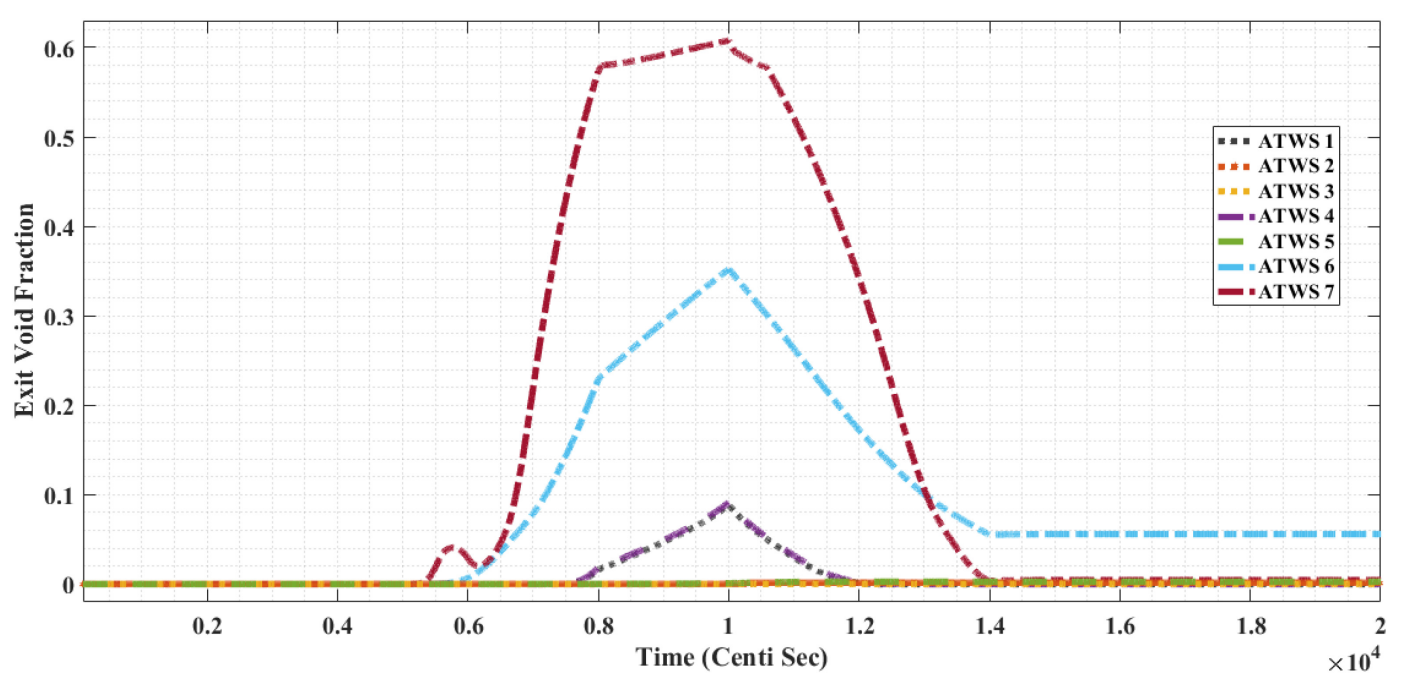

FIGURE 9 | Exit void fraction during ATWS scenarios.

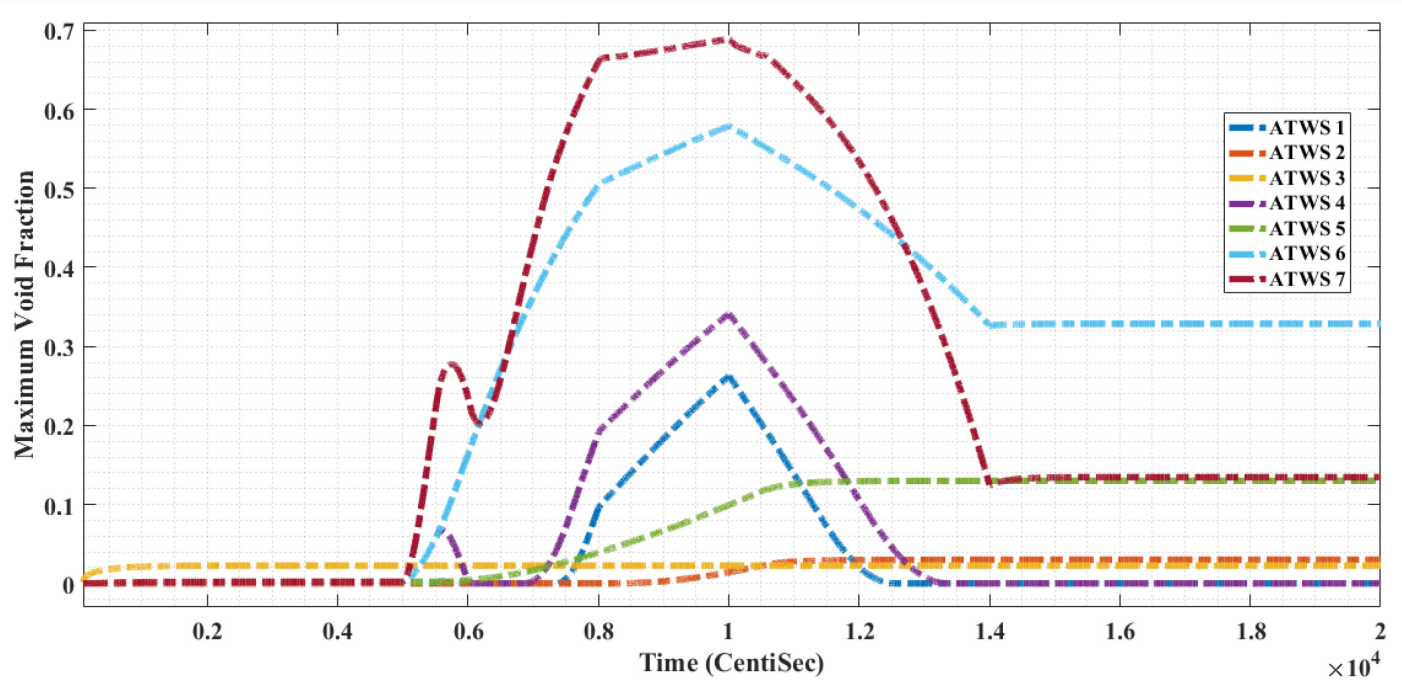

FIGURE 10 | Maximum void fraction during ATWS scenarios.

the research methodology is specified; then, a general overview of simulation using COBRA-EN code is presented. Next, based on such neutronic calculations as flux distribution, peaking factors, and relative power are described with the help of MCNPX 2.7. Additionally, the fourth stage provides specifications related to a VVER1000/446 reactor including SCRAM conditions, uncertainties, accident scenarios, and model validation.

\section{Methodology}

The relevant methodology algorithm is illustrated in Figure $\mathbf{1 .}$ In this study, the primary boundary conditions alongside core sub-channels based on the FSAR for an MCNPX 2.7 model are implemented. Then, after validating the model, the neutronic steady-state conditions are calculated. The obtained results are considered as the initial and the boundary conditions for
COBRA-EN model computations. The boundary conditions are updated by COBRA-EN while transient analysis is in progress. After implementing and validating the model in COBRA-EN, accident scenarios are applied and the outputs are extracted.

\section{Thermal-Hydraulic Simulation Model}

The COBRA-EN code is employed as a thermo-hydraulic code for "core analysis" and "sub-channel analysis" calculations. This code performs calculations based on discretization of the domain starting its calculations from a steady-state condition. Its relevant input parameters, e.g., axial and radial power peaking factors originate from the MCNPX 2.7 code. The core thermohydraulic calculations, while considering correction coefficients, are carried out based on two-phase governing equations of mass, energy, and momentum. As calculations related to the 


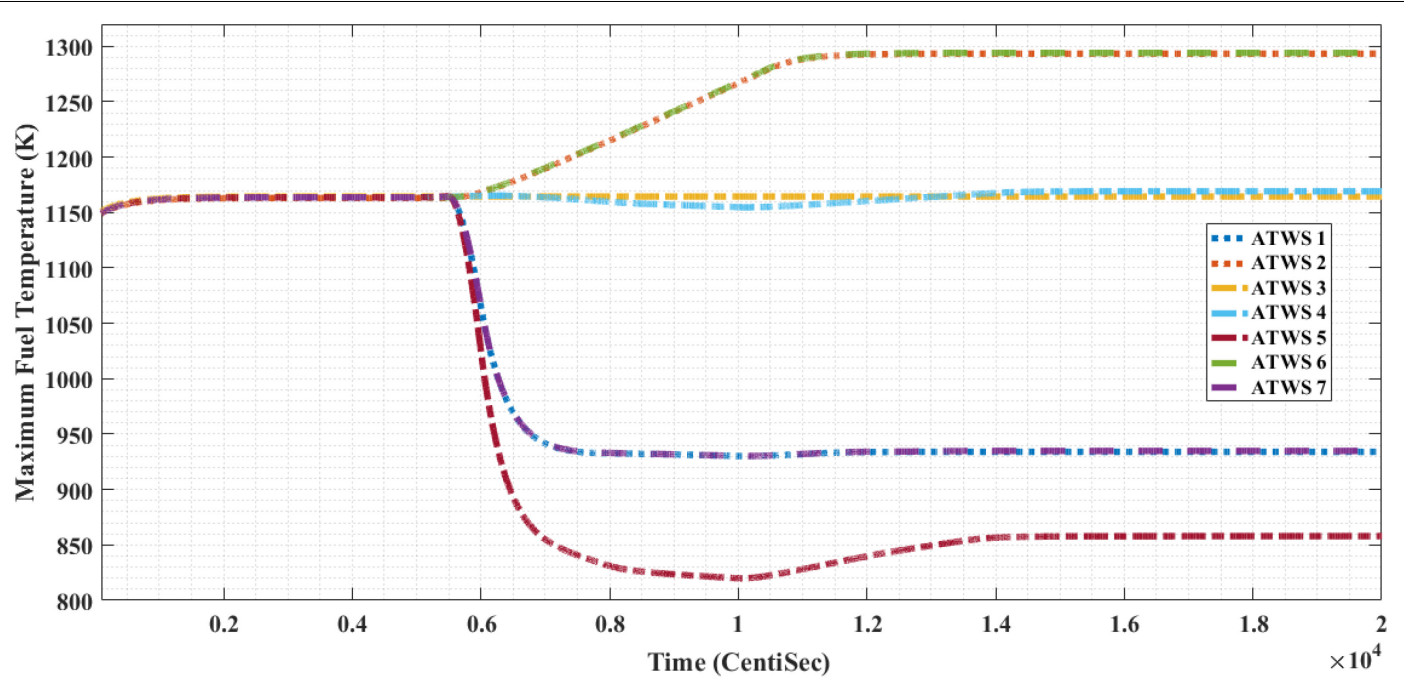

FIGURE 11 | Maximum fuel temperature during ATWS scenarios.

heat flux, void fraction, and slip ratio are performed, in compliance with EPRI (Electric Power Research Institute), the Levi correction coefficients are applied. To perform enthalpy calculations in a two-phase mode, the slip ratio and the steam quality equations are obtained through applying Zuber-Findlay correction factors (Constantin and Foias, 1988; Kataoka and Serizawa, 1989).

In order to acquire the calculation results on the critical flux and temperature; in the hot channel- the critical heat flux correlation coefficient can be used as part of the surface heat transfer model (Ammirabile, 2010). However, EPRI correlation coefficients are exploited to approximate the heat transfer between the nuclear boiling point and the subcritical boiling (Reddy et al., 1982).

Figure 2 shows the numbering related to fuel channels and rods for COBRA-EN code input. The number of fuel rods in the middle of the circles is indicated in black, while the number of cooling channels between the sides is represented in red. Figure 3 displays a general map of the core and the calculations performed as a sub-channel analysis along with details related to each of the rods and channels. There are 311 and 657 fuel rods and coolant channels in the assembly, respectively.

\section{The Neutronic Simulation Model}

MCNPX 2.7 code is used to obtain the axial and radial output power peaking factors, flux distribution, and relative power calculations as COBRA-EN code input. MCNPX 2.7 code is one of the beam computational codes based on Monte Carlo calculations (Waters, 2002). Figure 3 shows the arrangement of the core originating from the FSAR 446/1000-VVER reactor together with details on MCNPX 2.7 model placements.

Figure 4 exhibits the location of the current study local blockage regarded as of the hotspots in the assembly. The latter point is placed at the location of $3.6 \%$ enrichment fuels and at the rods' inlet constituting $20 \%$ height of the rod.

\section{VVER-1000/446}

The study case is a Russian VVER-1000/446 Reactor whose specifications are presented in Tables 1, 2, functioning, respectively, as inputs to COBRA-EN and MCNPX 2.7 codes. As can be seen, Figure 2 represents channel and rod placements related to the input of COBRA-EN code.

\section{SCRAM Conditions}

Scrams related to reductions in the mass flow rate, forming the major foundation of the present research, are listed in Table 3 which includes both horizontal rows and vertical columns. The synchronicity of the two events indicated can precipitate SCRAM conditions. Crucially, the criteria for SCRAM conditions occurring mostly depend upon in-core sensors and how quickly wide-ranging or close events are detected. For example, MDNBR (minimum departure from nucleate boiling ratio) estimation is only possible in very limited areas of the thermometer availability and not being possible in the case of local mishaps. Therefore, despite the occurrence of local melting and under 1 for MDNBR, the possibility of SCRAM happening due to local MDNBR is nearly eliminated (Automatic Exchange Of Information [AEOI], 2007).

\section{Local Blockage Accidents}

Events leading to these accidents are frequently a combination of Anticipated Transients Without Scram (ATWS). According to safety limits listed in Table $\mathbf{3}$, none of the accidents resulted in exceeding safety limits and prompting SCRAM command.

Three significant events and their combinations, including basic accidents involving single pump failure (RCP), blockage due to trapping leftovers from maintenance procedure, fuel ballooning, and reactor transient operation are among the issues investigated. Also examined are the effects of some other design parameters, e.g., grid spacer and cross flows.

The accidents mentioned might lead to a positive void fraction, the worsening of which can bring about higher vapor 


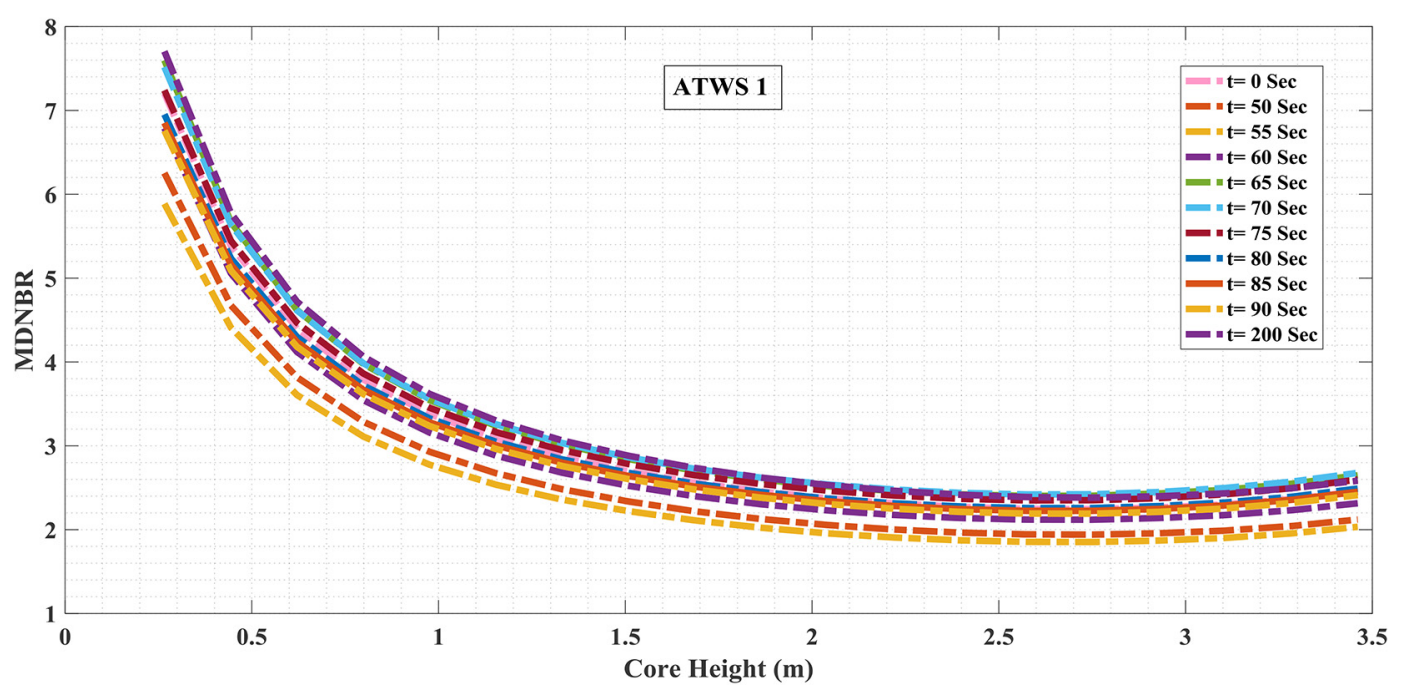

FIGURE 12 | MDNBR in core heights during ATWS 1.

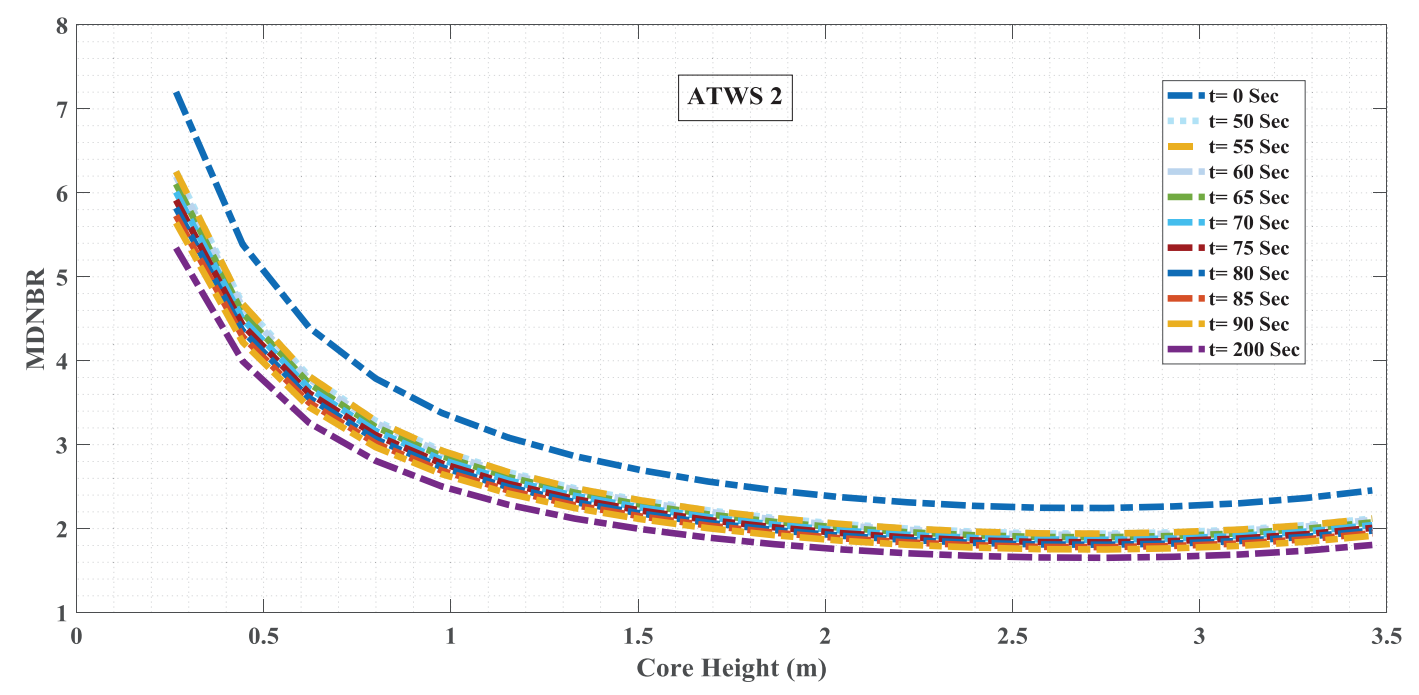

FIGURE 13 | MDNBR in core heights during ATWS 2.

ratios and local fuel melting. It should be noted that the mishaps initiate from steady-state conditions, by definition, from 0 to 50 s. Table 4 lists ATWS scenarios for localized flow blockage. Remarkably, all accidents hitherto referred to could create aggravated conditions when combined together.

\section{ATWS 1}

In the ATWS1 scenario, starting from the 50th to the 80th s and then jumping toward the 100th s, the mass flow rate is reduced to 82 and $78 \%$ of its nominal value due to a single RCP pump failure. It is to be noted that the relative power level from the 55th to 60 th s changes $66 \%$ of its nominal value, at which stage it remains constant based on ATWS documentations. Simultaneously, the total core pressure, along with the core flow rate, decreases up to $80 \%$ of their nominal values in the 100 th s. However, due to the pressurizer's effect, the pressure starts to jump again to $96 \%$ its nominal value which remains constant until the 140th s.

\section{ATWS 2}

In the ATWS2 scenario, the core outlet rate and the inlet flow rate, in transient analysis, remain constant. The relative power level reaches $117 \%$ from the 55 th to the 100 th $\mathrm{s}$, at which point it remains constant. The overall pressure of the core remains constant and under control.

\section{ATWS 3}

As for ATWS3, this is a fixed event from neutronic and thermohydraulic points of view, so the mass flow, power, and reactor pressure are being constant undergoing no change. All transient variations amount to local conditions. 


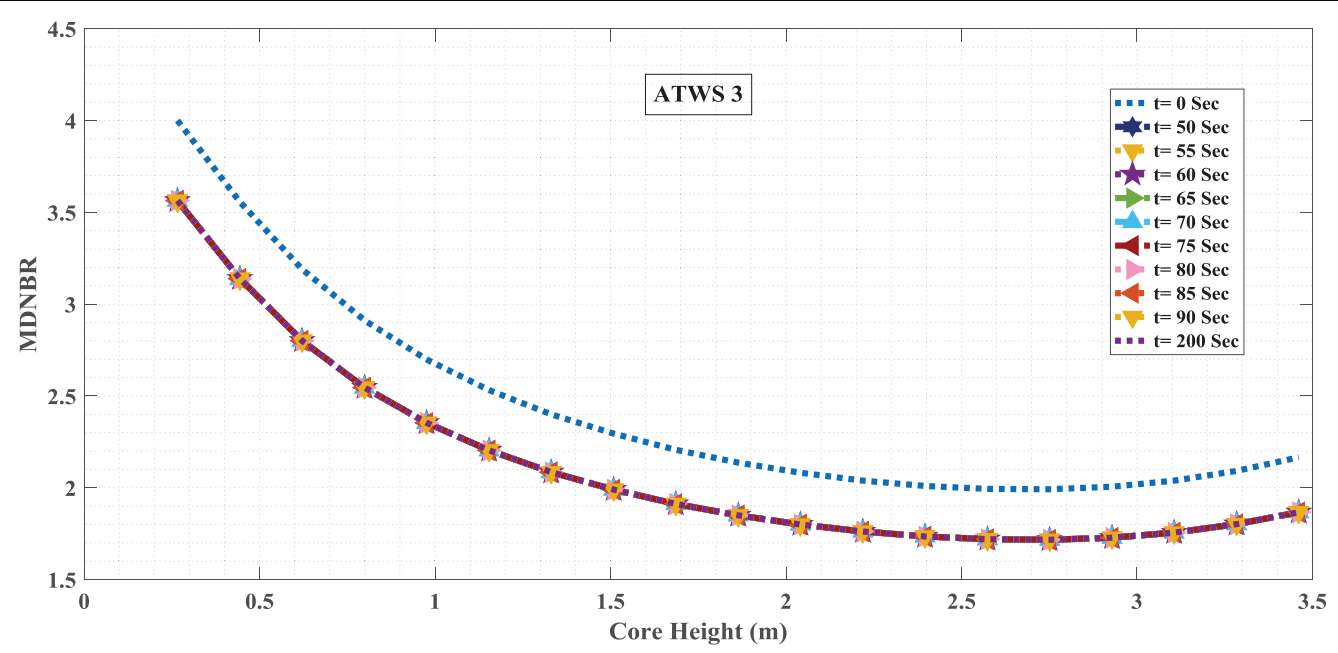

FIGURE 14 | MDNBR in core heights during ATWS 3.

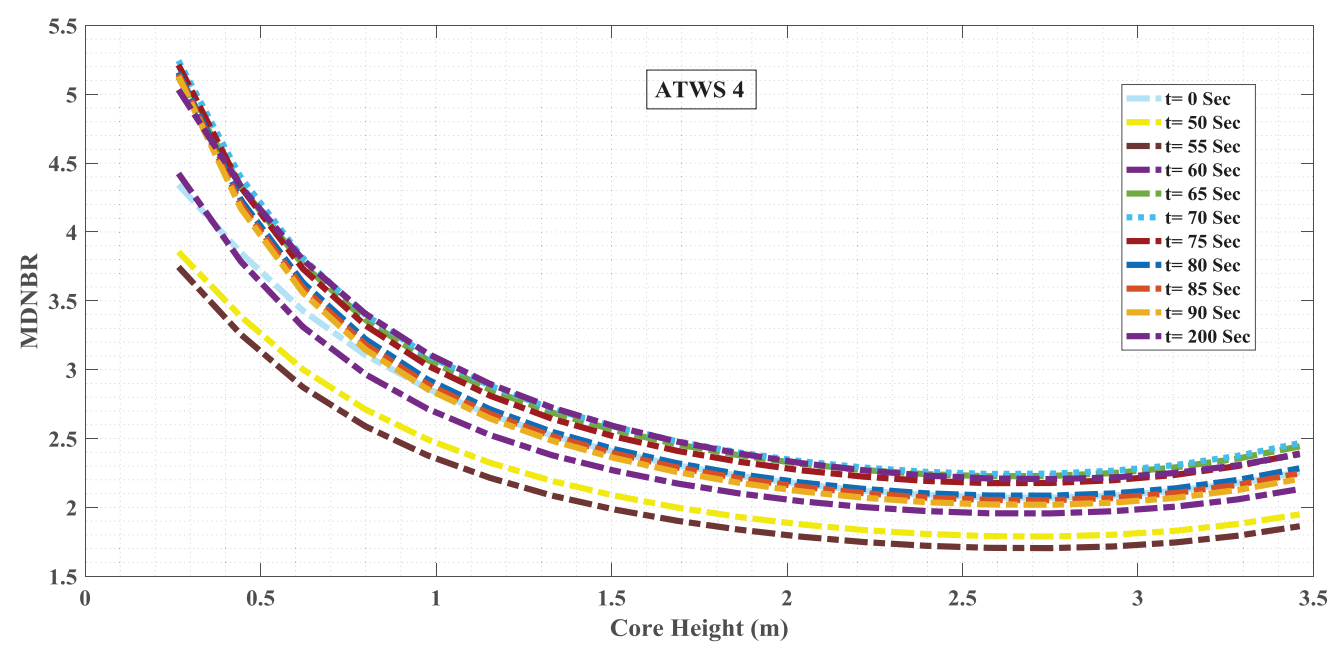

FIGURE 15 | MDNBR in core heights during ATWS 4.

\section{ATWS 4}

As was mentioned in the introduction part, the three basic scenarios are as follows: ATWS1, ATWS2, and ATWS3. The next four scenarios, ATWS4, ATWS5, ATWS6, and ATWS7, are considered combined scenarios occurring under reactor operation conditions which might culminate in grave conditions. In the ATWS4 scenario, a blockage accident is considered, along with an increase in the power level to its maximum value. Hence, the transient flow from the core remains constant. Based on this scenario, the relative power level increases from the 55th to the 105th s reaching up to a $117 \%$ level, at which point it remains constant. Based on the ATWS4 scenario, the core pressure remained constant.

\section{ATWS 5}

The ATWS5 scenario is a possible combined scenario consisting of a combination of local blockage at the channel entry point and a pump failure. In the transient flow from the core, from the 50th to the 80th s, the mass flow rate is reduced to $82 \%$ of its nominal value. It went back to $78 \%$ of its nominal value by the 100 th s, however. Based on this scenario, the relative power level from the 55 th to the 105 th $\mathrm{s}$ reaches a $66 \%$ level and remains constant.

\section{ATWS 6}

The ATWS6 scenario is a possible combined scenario comprising one RCP pump failure, $90 \%$ blockage in the hot channel entrance, and control rod failure in the dropdown. As well, it is noted that total events happening in the case of ATWS1 are observable in this scenario.

\section{ATWS 7}

The ATWS7 scenario is a combination of local blockage at the channel's entrance and a failure of two pumps. In this event, from the 50th to the 80th s, the mass flow rate is reduced up to a $56 \%$ 


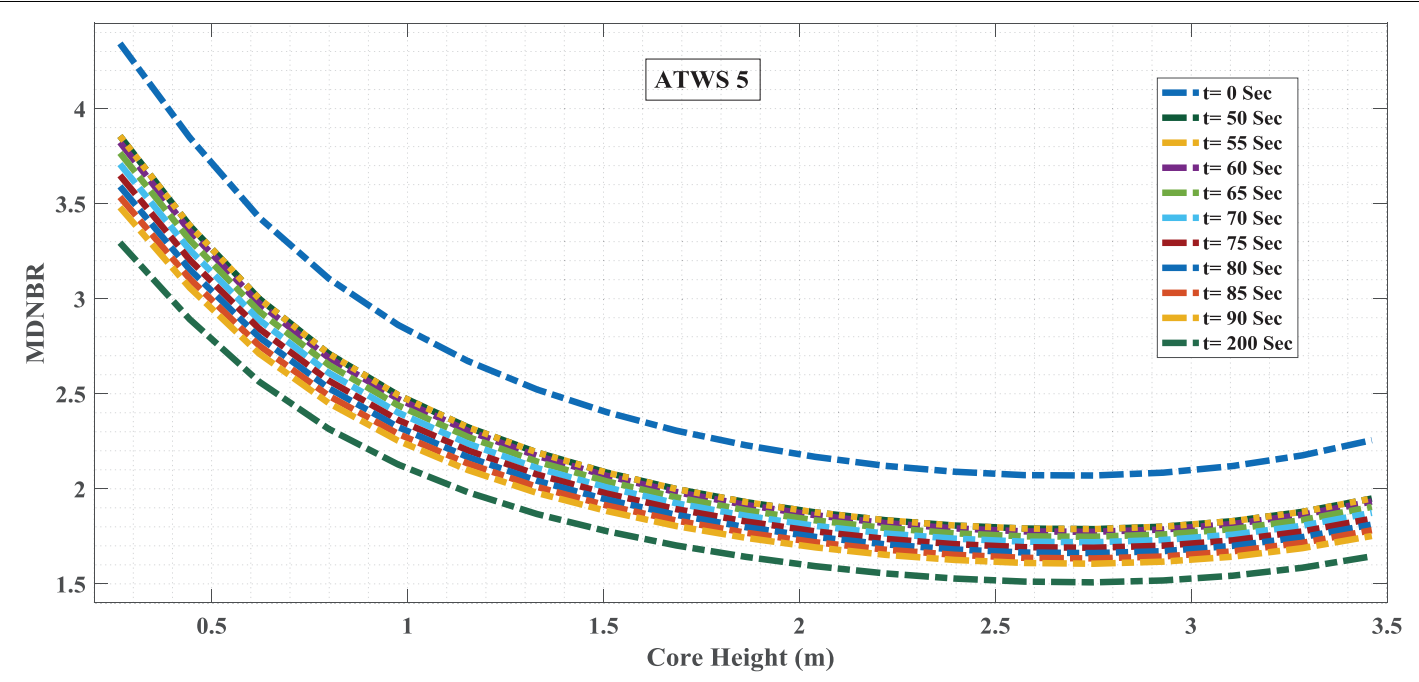

FIGURE 16 | MDNBR in core heights during ATWS 5.

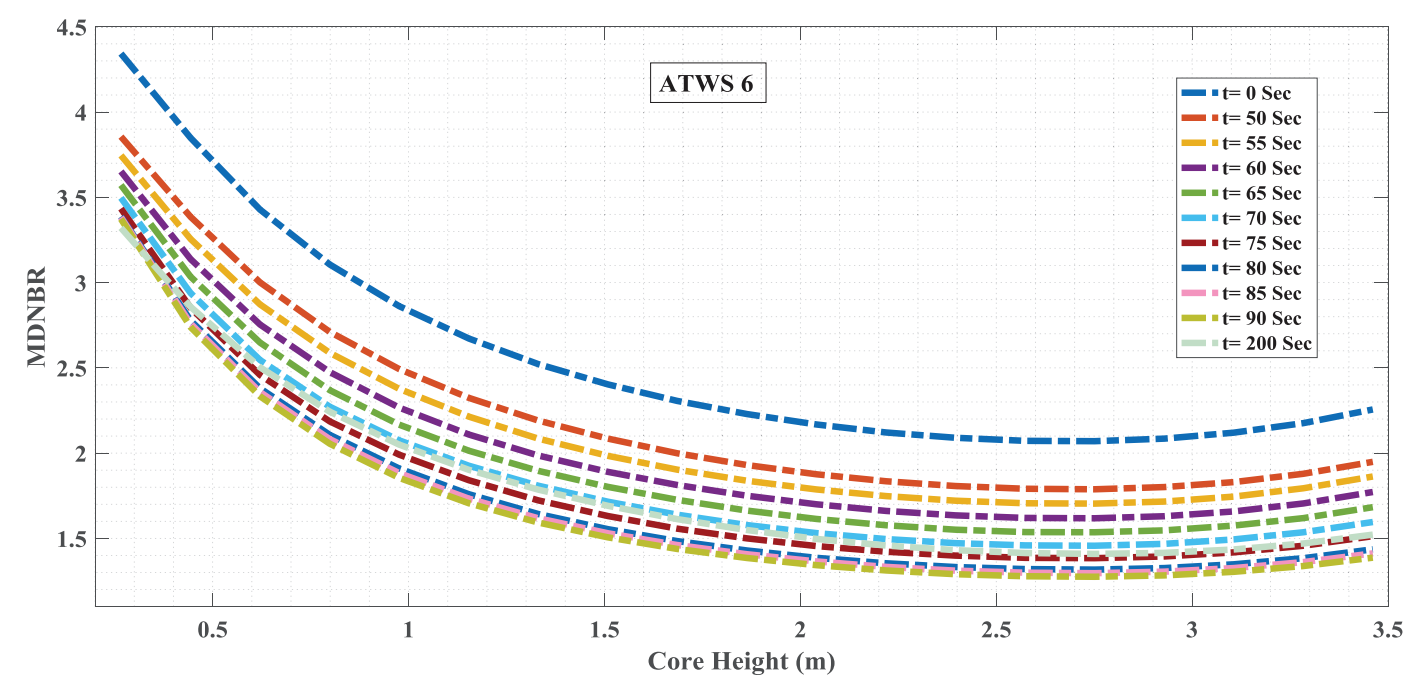

FIGURE 17 | MDNBR in core heights during ATWS 6.

level due to the failure in two pumps, following which, it reaches a $50 \%$ level in the 100th s.

\section{The Model Validation}

In order to validate the performed calculations, steady-state results are compared with those of other studies and the FSAR data, given in Table 5. It should be clear that all through these conditions and the singularity of accidents under investigation, no approved reference is available to check the data against; however, appropriate conformity in the steady state and other accidental conditions do have references available.

\section{Uncertainty in the Obtained Results}

It is assumed that the results obtained from COBRA-EN code calculations might slightly differ from the actual values under operational conditions. Therefore, uncertainty analyses have been performed, the results of which are presented in Table 6 (Avramova et al., 2009).

\section{RESULTS}

This section provides the research results on the core relative power, fuel, clad, coolant temperatures, core pressure, void fractions, and MDNBR quantities during ATWS scenarios implemented in the COBRA-EN code and MCNPX 2.7.

\section{Core Relative Powers During the Above ATWS Scenarios}

The common point of all accidents investigated consists of stable system conditions prior to applying the accidents. Figure 5 depicts core relative power during ATWS scenarios. It is 


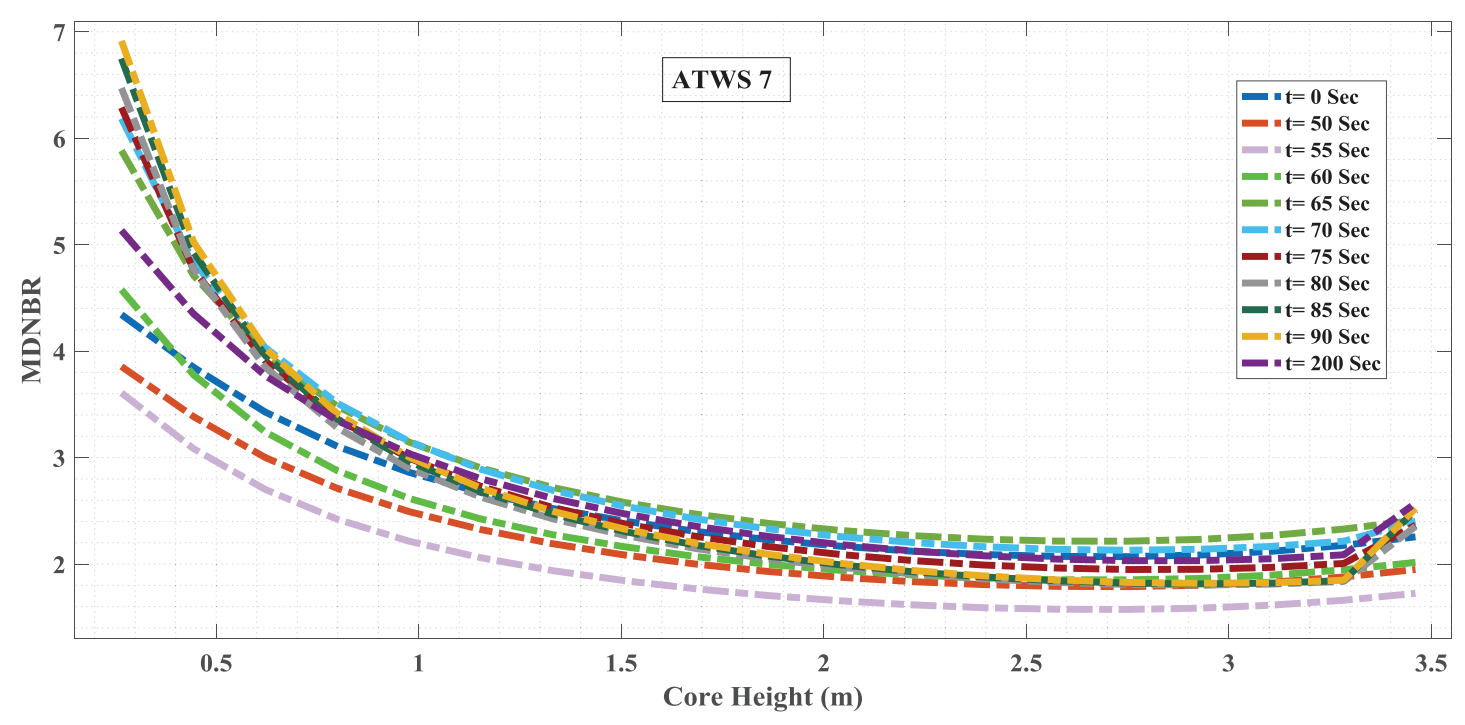

FIGURE 18 | MDNBR in core heights during ATWS 7.

to be noted that the transient algorithm of relative power during accidents is attributable to the boundary conditions. The implemented boundary conditions and the geometrical conditions are precisely extracted from ATWS and FSAR documents. Moreover, power peaking factors are considered based on MCNPx 2.7 output results. As shown in Figure 5, the relative transient power in ATWS3-related to hot channel blockage-undergoes no change.

In scenario ATWS6, the amount of power remains constant as the blockage prevents control rods from falling. Based on descriptions given for ATWS1 and ATWS5 scenarios, the relative power sharply declines to a $66 \%$ level within $5 \mathrm{~s}$. Incidentally, in the case of ATWS2 and ATWS4 scenarios, there is a power rise up to $17 \%$.

The issue of the increase occurred in the form of a ramp slope from the 55 th to the 100th s.

Finally, in the case of the ATWS7 scenario, due to the failure of two RCP pumps (crossover), the power level reduced up to $52 \%$ of its nominal value.

TABLE 7 | Comparison of SCRAM limits and maximum quantities at ATWS scenarios.

\begin{tabular}{lcc}
\hline Parameter & $\begin{array}{c}\text { SCRAM Criteria } \\
\text { in FSAR }\end{array}$ & $\begin{array}{c}\text { Max quantity } \\
\text { during the } \\
\text { accidents }\end{array}$ \\
\hline $\begin{array}{l}\text { The mass flow rate } \\
\text { reduction }\end{array}$ & $50 \%$ & $32 \%$ \\
$\begin{array}{l}\text { Pressure drop } \\
\text { reduction during } \\
\text { channel } \\
\begin{array}{l}\text { Entrance coolant } \\
\text { temperature } \\
\text { DNBR }\end{array}\end{array}$ & $7 \%$ & $2 \%$ \\
\end{tabular}

\section{Maximum Coolant Temperature During ATWS Scenarios}

As is indicated in Figure 6, maximum coolant temperatures in transition conditions eventually reach $598^{\circ} \mathrm{K}$, which value does not exceed the safety limits and the amount needed for the activation of the SCRAM command.

\section{Core Pressure During ATWS Scenarios}

The core pressure transition scenarios are derived from ATWS Documents and minor fluctuations are disregarded due to the main goal of the research. Figure 7 demonstrates that in ATWS2, ATWS3, and ATWS4 scenarios, the total core pressure does not change and remains constant. In ATWS1, ATWS5, ATWS6, and ATWS7, the core pressure reduces to 80,80 , and $55 \%$ of their nominal values. However, due to the pressurizer effect, the stated values, respectively, return to 96,96 , and $94.0 \%$ of their nominal values. And so, due to a drop in the core pressure, these events neither exceed safety limits nor satisfy SCRAM criteria.

\section{The Mass Flow Rate During ATWS Scenarios}

Figure 8 clearly shows maximum flow rate changes occurring in the case of the ATWS7 scenario, i.e., a change of $13 \%$. In the ATWS1, ATWS6, and ATWS5 scenarios, the mass flow rates decrease to $78 \%$ of their nominal values owing to a pump failure. In the ATWS2, ATWS3, and ATWS4 scenarios, however, the core flow rate almost remains constant. In ATWS7, the rate decreases to $50 \%$ of its nominal value due to the failure of two RCP pumps.

\section{Maximum Void Fraction During ATWS Scenarios}

As is inferred from the data given in Figures 9, 10, all these accidents, including the three basic events as well as four combinations of these accidents have a positive void 
fraction. Figure 10 clearly shows that void fraction forms during the accidents under investigation, and under most pessimistic projections- including higher core pressure rate, higher inlet temperature, and lower flow rate- the result could be a higher void fraction. Clearly, in more than $40 \mathrm{~s}$, something above 0.6 of void fraction has occurred in some channels. This cannot trigger SCRAM conditions. Fuel local melting could happen, however.

\section{Maximum Fuel Temperature Levels During ATWS Scenarios}

Figure 11 clearly shows that maximum fuel temperature occurs in the ATWS2 and ATWS6 accidents, being almost at $1,298^{\circ} \mathrm{K}$. It is to be reminded that the safety criteria for the clad deformation are $1,500^{\circ} \mathrm{K}$ (Lewis, 1977) which is a far higher value than those obtained during the latter events. It is interesting to note that the temperature ranges reported in Figure $\mathbf{1 1}$ are related to values lying in the vicinity of in-core thermocouple areas. But, in terms of hotspots, the situation is different and the temperature rises faster than the melting point during positive void fractions.

\section{The MDNBR in Core Heights During the ATWS Scenarios}

Figures 12-18 illustrate MDNBR changes during the ATWS scenarios. As is shown in the latter Figures, the MDNBR value at the thermometer locations is above 1.2, while the local value is less than 1, which value can be attributed to local burnout and melting. Consequently, despite the fact that local burnout and melting occur, the MDNBR-based SCRAM does not take place.

\section{Comparing SCRAM Limits and Maximum Quantities at ATWS Scenarios}

Table 7 shows SCRAM criteria for quantities under the most pessimistic circumstances in the case of studied scenarios. It is revealed that the SCRAM criteria are neither attained nor exceeded (Automatic Exchange Of Information [AEOI], 2007). Mass flow rate reduction, pressure drop, coolant temperature, and MDNBR-in the mentioned order-have $18 \%, 5 \%, 0.2^{\prime}$ ' , and 0.3 distances from meeting the SCRAM criteria.

\section{REFERENCES}

Ammirabile, L. (2010). Studies on supercritical water reactor fuel assemblies using the sub-channel code COBRA-EN. Nucl. Eng. Des. 240, 3087-3094. doi: 10. 1016/j.nucengdes.2010.05.025

Arshi, S. S., Mirvakili, S. M., and Faghihi, F. (2010). Modified COBRA-EN code to investigate thermal-hydraulic analysis of the Iranian VVER-1000 core. Prog. Nucl. Energy 52, 589-595. doi: 10.1016/j.pnucene.2010.01.005

Automatic Exchange Of Information [AEOI] (2007). "Inspection and control system (I\&A)," in Final Safety Assurance Report, (Moscow: Federal State Unitary Enterprise).

Avramova, M., Ivanov, K., Krzykacz-Hausmann, B., Velkov, K., Pautz, A., and Perin, Y. (2009). "Uncertainty analysis of COBRA-TF void distribution

\section{CONCLUSION}

The present study was designed to carry out transient analyses of scenario accidents that might lead to partial or local melting of the fuel clad while the reactor was in operation, that is, a situation far from SCRAM condition. Three main ATWS accidents alongside four combinations of these accidents are investigated. Similarly explored are combinations of RCP pump failures, blockages at the coolant channels, and relative power increases. Thermohydraulic calculations were performed using COBRA-EN code as well as power distribution profile computations based on MCNPX 2.7 code. The maximum mass flow rate reduction in all scenarios observed was $18 \%$ less than the SCRAM threshold. The maximum channel pressure drop in all scenarios was $470 \mathrm{kPa}$ short of the allowed limit. An investigation of the scenario events revealed that the maximum temperature of the fuel clad exhibits a $204^{\circ} \mathrm{K}$ difference from the SCRAM high point and the lowest MDNBR value determined was 1.5 , which rate did not exceed the SCRAM limits. Therefore, SCRAM did not occur in any of the investigated accidents, but the void fraction was up in $70 \%$ of channels within a period of $12 \mathrm{~min}$. As a result, under normal operating conditions, there might exist burnout situations in which local fuel melting could result. It was shown that under most pessimistic projections, the uncertainty in the results is $1 \%$ - a value quite compelling in uncertainty studies. It is worthy of mention that a pressurizer effect was also noticeable in the transient analysis of the accidents. As is shown by the simulation results in the current study, there is a possibility that local blockages might lead to fuel melting during the time when the above scenarios are in progress. This calls for NPPs to have a local blockage diagnosis system in place.

\section{DATA AVAILABILITY STATEMENT}

The original contributions presented in the study are included in the article/supplementary material, further inquiries can be directed to the corresponding author/s.

\section{AUTHOR CONTRIBUTIONS}

All authors listed have made a substantial, direct and intellectual contribution to the work, and approved it for publication.

predictions for the OECD/NRC BFBT Benchmark," in Proceedings of the International Conference on Advances in Mathematics, Computational Methods, and Reactor Physics (M\&C’09), (La Grange Park, IL: American Nuclear Society).

Constantin, P., and Foias, C. (1988). Navier-Stokes Equations. Chicago, IL: University of Chicago Press.

Dehjurian, H. N. (2015). Analysis Of Conjugate Conduction-Convection Heat Transfer In Nuclear Reactor Fuel Assembly, in Mechanical. Shiraz: Shiraz University.

Du, P., Shan, J., Zhang, B., and Leung, L. K. (2019). Thermal-hydraulics analysis of flow blockage events for fuel assembly in a sodium-cooled fast reactor. Int. J. Heat Mass Transf. 138, 496-507. doi: 10.1016/j.ijheatmasstransfer.2019.04.073

Gharari, R., Mataji, K. N., Saffari, N. A., and Nasiri, A. (2016). "Study of flow path blockage accident around a hot fuel 
rod," in Proceedings of the 1st National Conference on PENPP, (Bushehr: AZAD university of bushehr).

Guo, Y., Wang, G., Qian, D., Yu, H., and Hu, B. (2018). "Analysis of Flow Blockage of a Single Fuel Assembly in the JRR-3 20MW Research Reactor," in Proceedings of the International Conference on Nuclear Engineering, (New York, NY: American Society of Mechanical Engineers), 51487.

Kataoka, I., and Serizawa, A. (1989). Basic equations of turbulence in gas-liquid two-phase flow. Int. J. Multiph. Flow 15, 843-855. doi: 10.1016/0301-9322(89) 90045- 1

Khamis, I. (2017). "SAMG-D: the IAEA training toolkit on the development of severe, accident management guidelines," in Paper Presented at Training Workshop on the Development of Severe Accident Management Guidelines Using the IAEA's Severe Accident Management Guideline Development Toolkit Presentations, (p. v), (Vienna: International Atomic Energy Agency (IAEA)).

Lewis, E. E. (1977). Nuclear Power Reactor Safety. New York, NY: John Wiley and Sons, Inc.

Liu, X. J., Yang, D. M., Yang, Y., Chai, X., Xiong, J. B., Zhang, T. F., et al. (2020). Computational fluid dynamics and subchannel analysis of lead-bismuth eutectic-cooled fuel assembly under various blockage conditions. Appl. Therm. Eng. 164:114419. doi: 10.1016/j.applthermaleng.2019.114419

Nakamura, H. (2014). Particle Modeling of Fuel Plate Melting during Coolant Flow Blockage in HFIR. PhD. Dissertation. Knoxville: University of Tennessee.

Rahm, T., Droin, J. B., Marie, N., Bertrand, F., and Marrel, A. (2019). Analysis of the total instantaneous blockage accident consequences in the innovative inherently-safe CADOR SFR core. Nucl. Eng. Des. 348, 78-89. doi: 10.1016/ j.nucengdes.2019.04.019
Reddy, D. G., Sreepada, S. R., and Nahavandi, A. N. (1982). Two-Phase Friction Multiplier Correlation for High-Pressure Steam-Water Flow, EPRI NP-2522, Research Project. Palo Alto, CA: EPRI.

Roychowdhury, D. G., Govindarajan, S., Chetal, S. C., and Bhoje, S. B. (2000). Design Approach to Local Blockages (IAEA-TECDOC-1157). Vienna: International Atomic Energy Agency (IAEA).

Sehgal, B. R. (2011). Nuclear Safety in Light Water Reactors: Severe Accident Phenomenology. Cambridge, MA: Academic Press.

Waters, L. S. (2002). MCNPX 2.7 User's Manual. Los Alamos, NM: Los Alamos National Laboratory.

Zhang, J., Yu, S., and Yan, Y. (2019). Fixed-time output feedback trajectory tracking control of marine surface vessels subject to unknown external disturbances and uncertainties. ISA Trans. 93, 145-155. doi: 10.1016/j.isatra.2019. 03.007

Conflict of Interest: The authors declare that the research was conducted in the absence of any commercial or financial relationships that could be construed as a potential conflict of interest.

Copyright (c) 2021 Salmassian, Rabiee, Nematollahi, Faghihi and Pirouzmand. This is an open-access article distributed under the terms of the Creative Commons Attribution License (CC BY). The use, distribution or reproduction in other forums is permitted, provided the original author(s) and the copyright owner(s) are credited and that the original publication in this journal is cited, in accordance with accepted academic practice. No use, distribution or reproduction is permitted which does not comply with these terms. 